$$
\text { DOE/PC/89879-T9 }
$$

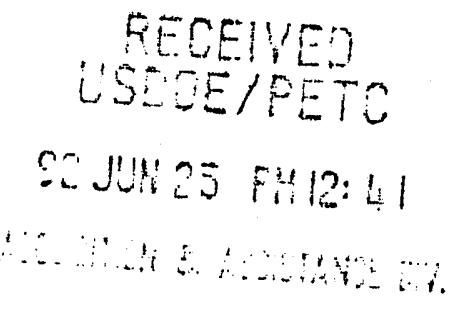

AWARD NO. DE-AC22-89PC89879 DOE/PC/89879--T9

DE92 016617

QUARTERLY REPORT 9

RESEARCH PERIOD 9/21/91 - 12/20/91

\title{
HIGH TEMPERATURE CERAMIC MEMBRANE \\ REACTORS FOR COAL LIQUID UPGRADING
}

\author{
Principal Investigator \\ Professor Theodore T. Tsotsis \\ Department of Chemical Engineering \\ University of Southern California \\ Los Angeles, California 90089-1211

\section{DISCLAIMER}

This report was prepared as an account of work sponsored by an agency of the United States This report was prepared as an account of work sponsored by an agency of the United ntates Government. Neither the United States Government nor any ag any legal liability or responsiemployees, makes any warranty, express or implied, or assumes any legal apparatus, product, or bility for the accuracy, completeness, or usefulness of any information, apparatus, product Referprocess disclosed, or represents that its use would not infringe privately owned re resice by trade name, trademark, ence herein to any specific commercial product, process, or service by trade ndorsement, recommanufacturer, or otherwise does not necessarily constitute or imply its endorserent The views mendation, or favoring by the United States Government or any agency thereof. The of the and opinions of authors expressed herein do not neces 


\section{TABLE OF CONTENTS}

\section{PAGE}

1. INTRODUCTION

1.1 Ceramic Membranes 1

1.2 Ceramic Membranes in Catalysis and Reaction Engineering 2

1.3 Metal and Glass Membranes 3

1.4 Alumina Membranes 4

2. PROJECT WORK PLAN 5

2.1 Task 1: Hydrocracking of Model Compounds in a 6 Membrane Reactor

2.2 Task 2: Hydrocracking of Model Compounds Using 9 Carbon-Coated Alumina Membranes

$\begin{array}{lll}2.3 & \text { Task 3: Asphaltene Upgrading in a Catalytic } & 10\end{array}$ Membrane Reactor

3. RESEARCH PERFORMED THIS QUARTER 11

4. LITERATURE REFERENCES 14 


\begin{abstract}
In this project we intend to study a novel process concept, i.e., the use of ceramic membranes reactors in upgrading of coal derived liquids. Membrane reactors have been used in a number of catalytic reaction processes in order to overcome the limitations on conversion imposed by thermodynamic equilibrium. They have, furthermore, the inherent capability for combining reaction and separation in a single step. Thus they offer promise for improving and optimizing yield, selectivity and performance of processes involving complex liquids, as those typically found in coal liquid upgrading.

Ceramic membranes are a new class of materials, which have shown promise in a variety of industrial applications. Their mechanical and chemical stability coupled with a wide range of operating temperatures and pressures make them suitable for environments found in coal liquid upgrading. In this project we will evaluate the performance of Sel-Gel alumina membranes in coal liquid upgrading processes under realistic temperature and pressure conditions and investigate the feasibility of using such membranes in a membrane reactor based coal liquid upgrading process. In addition, the development of novel ceramic membranes with enhanced catalytic activity for coal-liquid upgrading applications, such as carbon-coated alumina membranes, will be also investigated.
\end{abstract}




\section{INTRODUCTION}

\subsection{Ceramic Membranes}

Ceramic membranes were first produced in the early seventies but until recently had found no extensive industrial applications. This in part was due to problems with past production techniques resulting in membranes of poor quality in terms of pore size uniformity and material strength. The picture is rapidly changing today. New techniques [1-4] for membrane preparation using the Sol-Gel process have been developed by industrial and government laboratories both in the U.S. and abroad. Several U.S. firms (ALCOA, Norton Co., DuPont and Alcan/Anotec) a number of European laboratories and at least one Japanese company (NGK Insulators) have ceramic membranes currently on the market, which in $1986[4,5]$ was estimated to be $\$ 200 \mathrm{M}$ and expanding at an annual rate of over $30 \%$.

The commercial ceramic membranes have good pore size uniformity, and thermal and mechanical properties superior to competitive polymeric, organic and metal membranes. Their superiority stems primarily from enhanced resistance to high temperatures $\left(1000^{\circ} \mathrm{C}\right)$ and corrosive environments commonly found in the chemical industry. Some of the best organic or polymeric membranes start to break down at about $100^{\circ} \mathrm{C}$ making them impractical for use in many industrial processes. Metallic membranes (like porous stainless steel) are susceptible to corrosion and their cost in 1986 was only $30 \%$ less than competitive ceramic membranes. Even in cases where polymeric or organic membranes are applicable, their ceramic counterparts have the distinct advantage that they can be thermally treated $\left(500^{\circ} \mathrm{C}\right)$ steam cleaned and sterilized.

The main client for ceramic membranes so far has been the food, pharmaceutical and electronics [6-14] industries, where such membranes are replacing organic and polymeric membranes for ultrafiltration, water purification and sterilization purposes. Ceramic membranes are also making inroads into other areas like the treatment of waste waters containing oily contaminants [15] and in bioreactor applications [16]. 


\subsection{Ceramic Membranes in Catalysis and Reaction Engincering}

An area for which ceramic membranes show potential for broad and significant applications is catalysis and reaction engineering. Many industrial catalytic reactions show low conversions and/or yields due either to unfavorable thermodynamics, product inhibition and undesirable side reactions. This in turn necessitates more severe operating conditions (which in turn require higher catalyst replacement rates) and costly separation operations. Hydrogenation and dehydrogenation reactions, hydroformylations, hydrations and dehydrations, olefin metathesis and partial oxidations are prime candidate reaction systems for the application of catalytic membrane reactor technology and could certain!y benefit from being conducted over a membrane.

Catalytic membrane reactors have the inherent capability for combining reaction and separation in a single unit operation (we define a membrane reactor as one in which the membrane, either functioning or not functioning as a catalyst, is an integral part of the reactor itself, to distinguish from the case where an individual separate membrane modulus immediately follows the reactor; the distinction is of importance since in the bioengineering literature such an arrangement is often also referred to as a membrane reactor). This, of course, represents a significant improvement over the two separate units operation just described, with the reaction and separation units completely divorced. Catalytic membrane reactors, however, offer a number of other distinct advantages over their traditional counterparts (packed, fluidized and trickle beds). The membrane provides for selective removal of one or more products and/or stable intermediates in parallel with the reaction, thus driving the reaction (to use equilibrium limited reactions as an example) continuously towards the product side and resulting in higher reactor conversions. In principle, but also in practice, one attains conversions higher than the ones expected from static equilibrium, thus limiting the need for high pressures and temperatures (which cause catalyst deactivation), reducing recycle and feed and downstream separation requirements. The membrane, furthermore, allows one to adjust and influence the surface concentration of the various reactant and/or intermediate species and therefore provides the flexibility for unique control of the reactor selectivity and product distribution. 


\subsection{Metal and Glass Membranes}

In the area of catalysis and reaction engineering the earlier efforts to use membrane reactor technology [17-18] utilized porous Vycor Glass tubes and the first reaction tested was the decomposition of $\mathrm{H}_{2} \mathrm{~S}$ to produce $\mathrm{H}_{2}$ and $\mathrm{S}$. Conversions as high as twice the equilibrium limit were observed. Glass membranes, have since then been utilized in other catalytic studies [19-20] for the catalytic dehydrogenation of cyclohexane to benzene over supported Pt catalysts. Most of the current literature (primarily from the Soviet Union and Japan) on catalytic membrane reactor applications involves the use of $\mathrm{Pd}, \mathrm{Pd}$ alloys with $\mathrm{Ru}, \mathrm{Ni}$ and various other metals from groups VI to VIII, and Pd coated Zirconia [21-36] membranes. The Soviet literature, in particular, is impressive and includes (by 1986, see [32]) 58 Soviet inventor's certificates and 86 European and American patents. They cover a number of hydrogenation and dehydrogenation reactions such as $\mathrm{CH}_{4}$ steam reforming, dehydrogenation of butene to butadiene and hydrogenation to butane, acetylene hydrogenation, dehydrogenation of 1-, 2-cyclohexanediol, hydrodemethylation of methyl and dimethyl napthalenes, dehydrogenation of isopropyl alcohol, dehydrogenation of cyclopentadiene and cyclopentene and the production of many specialty chemicals [32]. The application of $\mathrm{Pd}$ membranes is based on the fact that $\mathrm{Pd}$ is highly permeable to $\mathrm{H}_{2}$ (a fact known since Thomas Graham first observed the phenomenon in 1866) but virtually impermeable to other gases, and, of course, liquids.

The development of Pd catalytic membranes has had a significant impact on proving and popularizing the concept of catalytic membrane reactors. The inherently low transmembrane luxes, however, combined with the high cost of these membranes and phenomena of metal intering, imbrittlement and fatigue have so far hindered the widespread industrial application of these membranes.

Some of the earlier efforts to use membranes in catalytic membrane reactor applications innolved the use of materials such as nonporous $\mathrm{Ag}$ and $\mathrm{CaO}$-stabilized zirconias exhibiting thanced oxygen anionic conductivity. A variety of reaction processes, primarily partial oxidation reactions, have been tested, some with considerable success $[25,37-42]$. 


\subsection{Alumina Membranes}

Alumina ceramic membranes have been tested successfully for various gas-phase separations [43-54], for water purification and sterilization operations in the food and pharmaceutical industries [6-14], and for treatment of wastewaters containing oily contaminants [15]. There are only a few reported studies, however, about their use in membrane reactor applications [55-57], mostly in the patent literature. This, in our opinion, is primarily indicative of the fact that only recently have high quality alumina based membranes become commercially available rather than of the industrial potential of these materials. Ceramic membranes have been synthesized by various techniques such as phase separation and leaching [58], slipcasting [59], SolGel [59-63], anodic oxidation [55, 56, 64, 65], track-etching $[66,67]$, direct pyrolysis $[68,69]$ and thin film deposition [70-72]. Most commercial alumina membranes are made by the Sol-Gel method. Flat alumina membranes prepared by anodic oxidation, for ultrafiltration and bioengineering applications, are also commercially available (made by Alcan/Anotec under the trade name Anopore).

Alumina and silica based membranes are currently being tested for membrane reactor applications by at least four academic and two industrial groups in the U. S., and by a number of research groups in Europe and Japan. Reactions currently under study range from equilibrium limited reactions, such as $\mathrm{H}_{2} \mathrm{~S}$ decomposition, hydrogenation, dehydrogenation and dehydration reactions to partial oxidation reactions, such as direct $\mathrm{CH}_{3} \mathrm{OH}$ synthesis from $\mathrm{CH}_{4}$. Preliminary experiments have been very encouraging. Ceramic membrane reactor technology, however, has still not reached its maturity and more must be learned before cramic membranes will find widespread industrial use and acceptance. In particular, issues of hydrothermal stability, resistance to coking and deactivation, mechanical strength and compatibility with other reactor materials have to be satisfactorily addressed. These are some of the technical issues and questions addressed in this proposal. 


\section{PROJECT WORK PLAN}

In this project we will study a novel process concept, i.e., the use of ceramic membrane reactors in upgrading of coal model compounds and coal derived liquids. As already mentioned in the introduction membrane reactors have been used in a number of catalytic reaction processes in order to overcome the limitations on conversion imposed by thermodynamic equilibrium. They have, furthermore, the inherent capability for combining reaction and in-situ separation in a single step and thus offer unique advantages in improving and optimizing yield, selectivity and performance of processes involving complex liquids, as those typically found in coal liquid upgrading.

This project is a collaborative research effort between the Department of Chemical Engineering at the University of Southern California, ALCOA Separations Technology Division, and UNOCAL, which is a no-cost contractor of this project. The principal investigator of the project is Theodore T. Tsotsis, a Professor of Chemical Engineering at the University of Southern California. The principal investigator of the ALCOA team is Dr. Paul K. T. Liu and the cortact person at UNOCAL is Dr. Ian A. Webster.

In general terms, the USC research team is responsible for constructing and operating the membrane reactor apparatus and for testing various inorganic membranes for the upgrading of coal derived asphaltenes and coal model compounds. The USC effort will involve the principal investigator of this project and two graduate research assistants. The ALCOA team is responsible for the preparation of the inorganic membranes, for construction and testing of the ceramic membrane modules, and for measurement of their transport properties. The ALCOA research effort will involve Dr. Paul K. T. Liu, who is the project manager of the ALCOA research team, an engineer and a technician. UNOCAL's contribution will be limited to overall technical assistance in catalyst preparation and the operation of the laboratory upgrading membrane reactor and for aialytical back-up and expertise in oil analysis and materials characterization. UNOCAL is a no-cost contractor but will be involved in all aspects of the project, as deemed appropriate in 
the technical capacity discussed above. The project involves three tasks, detailed description of which follows.

\subsection{TASK 1: Hudrocracking of Model Compounds in a Membrane Reactor}

This task will utilize coal model compounds to be decided in discussions between the DOE project manager and the USC, UNOCAL and ALCOA groups. The task will involve the hydrocracking of the model compounds over an alumina ceramic membrane placed in the membrane reactor. The following detailed experimental plan will be used for the investigation.

Preliminary experiments will be carried out in a batch autoclave type membrane reactor apparatus, a schematic of which is shown in Fig. 1. This apparatus consists of a single high pressure autoclave modified appropriately so that one can mount several ceramic membranes in its interior. To initiate the experiments the reactant solution (i.e., the model compounds dissolved in an appropriate solvent) will be loaded in the interior (or the exterior) of the ceramic membranes, the autoclave (or the interior of the membranes) will be loaded with pure solvent and pressurized under $\mathrm{H}_{2}$. The anodic ceramic alumina membrane will be rendered catalytic, by impregnating with Mo promoted with $\mathrm{Co}$ or Ni. Typically, extra-pore $\mathrm{MoO}_{3}$ represents less than $0.1 \%$ of the total metal content in the membrane and its effect is rather insignificant. If the need arises, however, it will be removed by direct chemical dissolution. The transport characteristics of the resulting catalytic ceramic membranes will be measured by techniques such as Ar permeability, diffusion of small molecules across the membrane, and the model compound molecules themselves (to be performed at USC and ALCOA) as well as by direct SEM and HREM microscopic observations (tests to be performed at UNOCAL). The overall metal content will be studied by using atomic absorption spectroscopy (at USC) and the intra-membrane metal distributions qualitatively by SEM/EDAX, and quantitatively by electron microprobe analysis (at UNOCAL). 


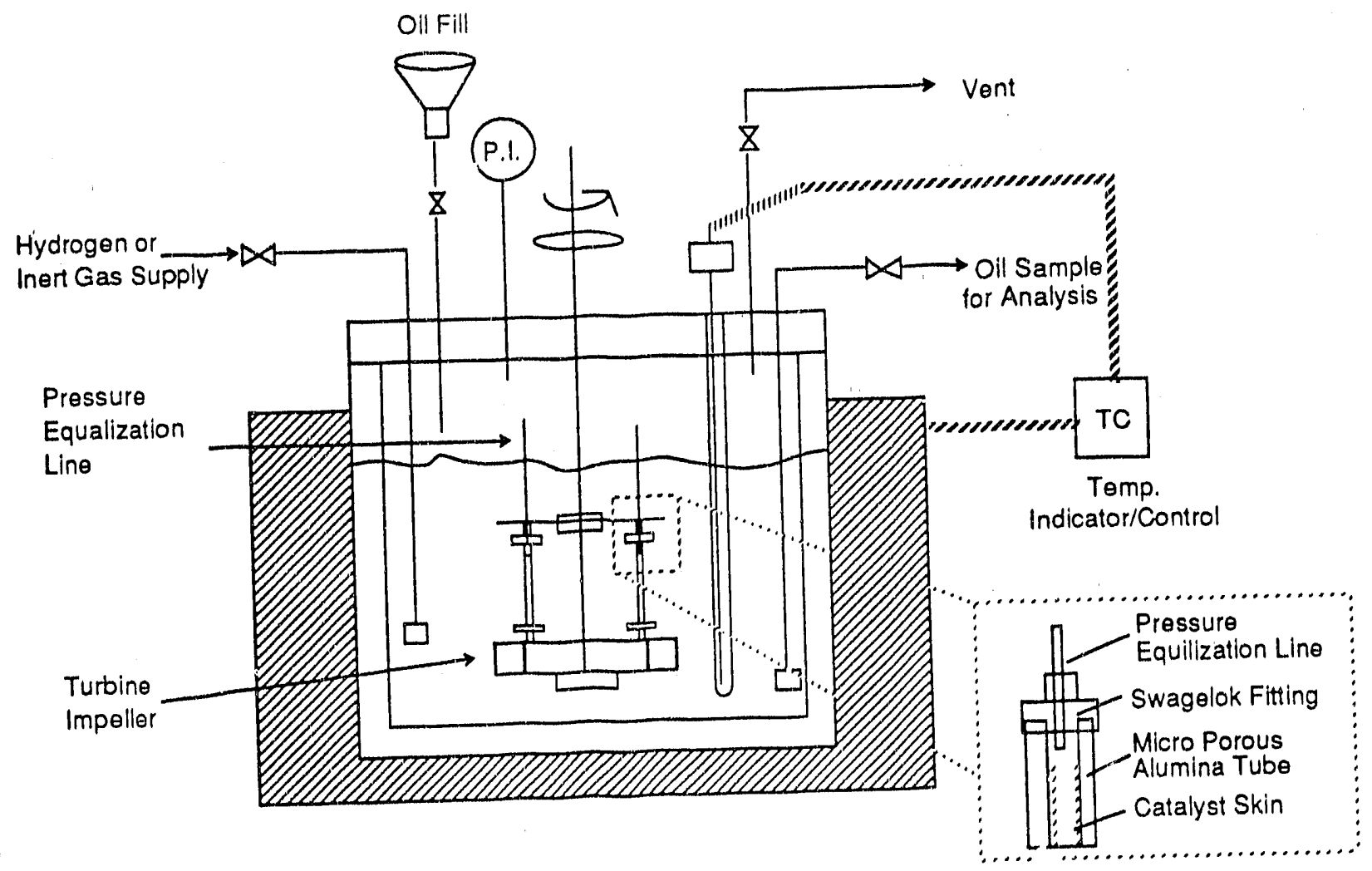

FIGURE 1: Batch Tubular Catalytic Membrane Reactor

Alumina membranes can be prepared with a controlled, small pore size. Depending on the molecular size of the model compound and its cracking products the differences in the diffusivity of reactants and products can be significant. Whether such differences really exist, and whether, based on the differences in diffusivities between reactants and products, the application of the membrane reactor concept will result in higher cracking reaction yields remains to be verified by the results of the experimental investigation.

Once the feasibility of the membrane reactor concept for the hydrocracking of model coal compounds is proven in the batch autoclave reactor subsequent experiments will be performed in a high pressure continuous membrane reactor apparatus. This is again a rather simple apparatus, a schematic of which is shown in Fig. 2. It will consist of two high-pressure holding autoclaves, two high-pressure LC syringe pumps, the stainless steel tubular membrane reactor housing the various ports and accessories, the temperature control, and product removal and sampling. The model compounds will be again dissolved in a suitable solvent and will be pressurized under hydrogen in 
one of the holding autoclaves. The second autoclave will contain the solvent, also pressurized under hydrogen. The two high-pressure LC syringe pumps will be utilized to circulate the two solutions on either side of the membrane in the ceramic membrane reactor.

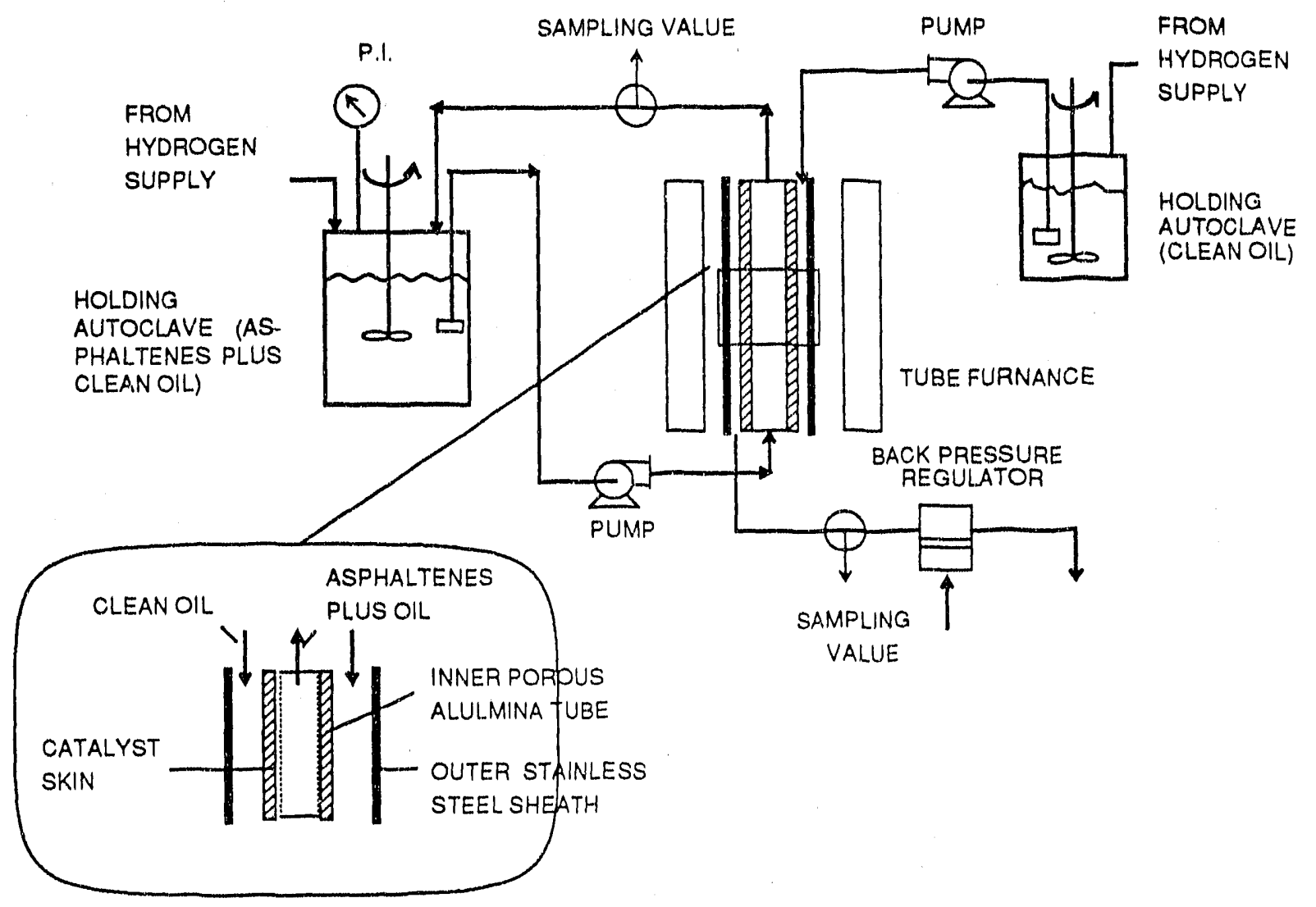

Figure 2: Schematic of the Membrane Reactor Apparatus

To summarize Task 2, the primary focus of our experimental study will be to prove that the membrane reactor concept works for processing of coal model compounds. Once accomplished, a number of other questions and issues will be addressed in detail, namely:

(i) Investigate the long term thermal and mechanical stability under hydroprocessing conditions of the alumina membranes.

(ii) Investigate the effect of various reactor parameters such as temperature, overall pressure, partial hydrogen pressure gradient across the membrane (while maintaining equal total pressure on either side of the membrane), solvent type, and 
feedstock tube and cell side liquid space velocities.

(iii) Investigate the effect of various membrane parameters such as pore size, thickness, overall metal loading, and various metal distributions along the membrane.

One important aspect of the work to be carried out in Task 1, but also in Tasks 2 and 3, is the development of appropriate housings and seals, which although peripheral are critical for the success of the research to be carried out in all Tasks. Commercial housings and seals designed for aqueous phase and low temperature applications with polymeric materials are not suitable. To improve high temperature applications of their membranes, ALCOA has developed two proprietary designs. A high temperature seal made up from graphite and a prototype ceramet end seal, a ceramic to metal connection. Both seals have performed well in laboratory tests. Although, it is anticipated that one of these two seals will be sufficient for the proposed research in Tasks 13 , if the need arises research will be undertaken by ALCOA for the development of seals appropriate for coal liquid upgrading applications.

\subsection{Task 2: Hydrocracking of Model Compounds Using Carbon Coated Alumina Membranes}

In this task, carbon-coated tubular membranes made by the Sol-Gel process will be utilized, provided by the subcontractor of this project, namely ALCOA which as a subcontractor to the University of Southern California, will provide the carbon-coated ceramic membranes with the complete characterization required for the proposed project. As described in the original proposal (see also Task 3), carbon-coated ceramic membranes could provide unique advantages for the proposed study. Such membranes will be prepared by ALCOA, using their existing products as a precursor.

As already described, the uniform pore structure and thin permselective layer of existing ALCOA ceramic membranes are appropriate for the separation of complex liquid containing compounds with a wide spectrum of molecular weight distribution. These membranes, furthermore, made of calcined alumina have excellent mechanical and temperature stability. A 
logical preparation method for the carbon-coated membranes is to modify the membrane surface of the existing alumina membranes with carbonaceous materials or their precursors.

Coatings for the ceramic membranes will have the following properties:

- The coating will be very uniform, so that it does not alter the pore size distribution.

- The coating will be very thin, so that the high original porosity is maintained. Moreover, the thin film coating should adhere strongly to the ceramic surface, so that delamination will not take place during permeation.

The permeation and transport of the carbon coated membranes will be tested at ALCOA, in an apparatus especially designed for this project.

\subsection{Task 3: Asphaltene Ungrading in a Catallic Membrane Reactor}

Ceramic tubular membranes (alumina and carbon coated alumina membranes provided by ALCOA - see Task 2) impregnated with Mo, and with $\mathrm{Co}$ and/or Ni as promoters, will be utilized. The same experimental procedures will be followed as in the model compound experiments. Th. asphaltenes will be isolated in polycrystalline form in a proprietary UNOCAL apparatus from a variety of coal liquids provided by DOE. The liquid composition on the membrane tube and shell sides will be analyzed for overall asphaltene content, for molecular weight distribution, for overall metal and S content, and for the chemical composition. Parameters to be investigated will be the total pressure and temperature, the effect of partial $\mathrm{H}_{2}$ pressure gradient across the membrane, the space times on the eube and shell side, and various metal profiles along the thickness and length of the membrane.

One of the most obvious concerns and possible drawbacks in the use of the catalytic membranes for model compound and asphaltene hydroprocessing is that metal and coke deposition would tend to decrease the membrane's pore volume and reduce its permeability and transmembrane flux. To address this problem, membranes with larger pore sizes (and, therefore, less selective) will be also examined, thus sacrificing initial activity in favor of optimal long-term

performance. The establishment of optimal operating conditions and policies, during coal liquid 
upgrading in a membrane reactor is one of the most important goals of this Task. Ceramic membranes with pore diameters varying from $40 \AA$ to several microns provided by ALCOA through the subcontract agreement (see Tasks 1-2 above) will be investigated.

Another avenue to be pursued is the use of highly specialized carbon-coated alumina membranes. Sulphided Co and Mo catalysts on carbon supports have been shown to be more active than commercial $\mathrm{Co}-\mathrm{Mo} / \mathrm{Al}_{2} \mathrm{O}_{3}$ catalysts for thiophene $\mathrm{HOS}$, for hydrogenation and for the upgrading of coal liquids. Although carbon based membranes are currently commercially available, their long-term mechanical and thermal stability under upgrading reaction conditions still remains a serious question. A compromise between the alumina and carbon membranes appears to be carbon-coated alumina membranes. Such membranes are not currently commercially available, but will be developed by ALCOA and they will be made available for Tasks 2 and 3 of this project.

The main goal of Task 3 is to investigate whether, by using catalytic membrane reactor technology during asphaltene hydroprocessing, one can obtain similar or better conversions and product compositions under milder experimental conditions with reduced metal loadings and catalyst replacement rates than that achieved in conventional processing.

\section{WORK PERFORMED THIS QUARTER}

The following were accomplished during this quarter.

(I) Neither the coal liquids nor the improved membranes were delivered during this quarter. In their absence, the USC team could not continue their membrane reactor experiments with coal liquids. Our attention during this quarter was focused on trying to perform a number of modifications on our apparatus that were deemed necessary during the time we were running our experiments, but were postponed because they involved considerable shutdown periods. Of partıcular concern to us was defining time zero in our 
hydroprocessing experiments. During this quarter, we improved upon our sample loading technique. All required modifications were performed at UNOCAL and involved no cost to DOE. The new modified reactor was tested using petroleum asphaltenes.

(II) We also addressed the issue of the sample size. The sample size is significant since it determines (i) the accuracy of the various tests we perform, and (ii) the degiee of perturbation introduced into the system. The model of our upgrading reactor was used to optimize the sample and sampling schedule technique.

(III) For the last year or so we have been puzzled by the discrepancy between the tests with coal and petroleum asphaltenes. In an attempt to understand the differences, we have taken a second look at some of the statistical models of asphaltenes previously developed by our group. We believe that the degree of polydispersity and the way it is affected by the reactor parameters/operation plays a determining role in the overall membrane reactor perfor mance. It was determined that a series of diffusion experiments with coal asphaltenes withdrawn from a hydrocracking reactor at various levels of conversion might offer valuable information on the operation of catalytic membrane reactors.

(IV) There has not been much interaction with the ALCOA group this quarter because they have been preoccupied with their buy-out by U.S. Filter and moving to new facilities. Hopefully, the modified membranes will be provided during the next quarter. 


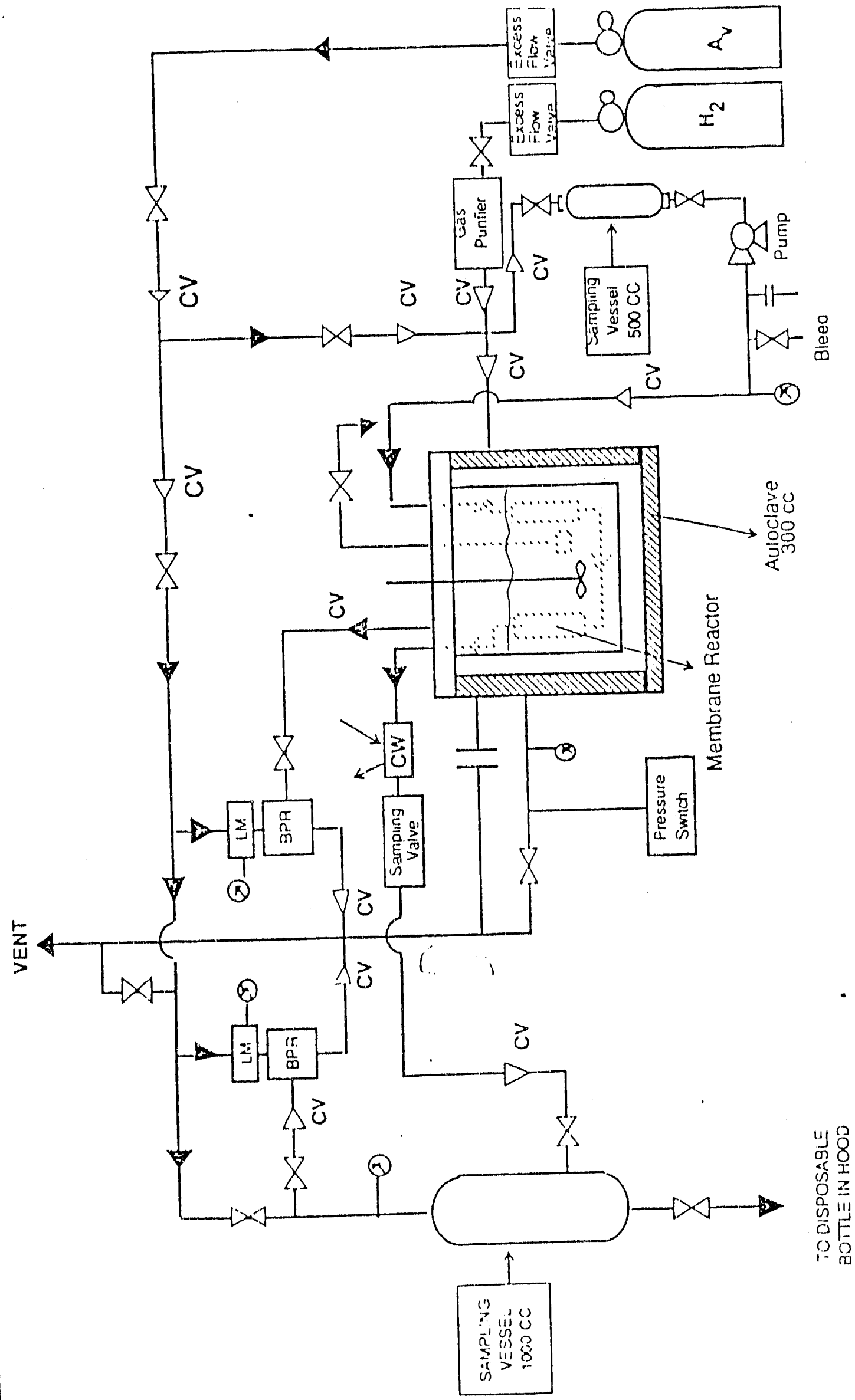

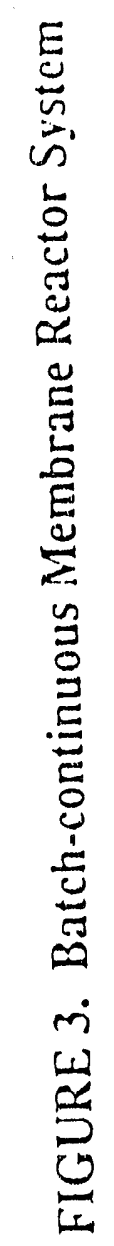

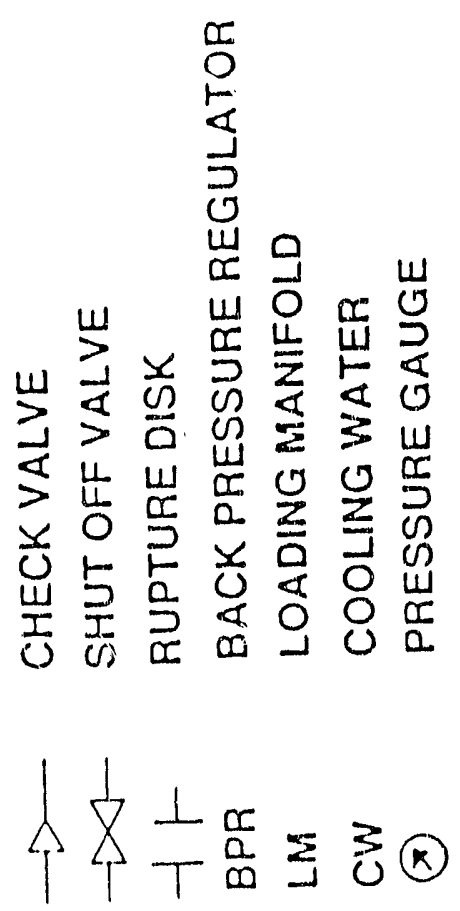




\section{REFERENCES}

1. Hench, L. L. and D. R. Ulrich, Eds., "Ultrastructure Processing of Ceramics, Glasses and Composites", Wiley 1984.

2. Schneider, S. J., Ed., "National Prospectus on the Future of the U.S. Advanced Ceramics Industry", NBS Report IR 85, 3240, Washington, D.C., 1985.

3. Hench, L. L., and D. R. Ulrich, Eds., "Science of Ceramic Chemical Processing", Wiley, 1986.

4. Hsieh, H. P., AlChE Symp. Ser., 261, 1, 1988.

5. "Ceramics Make Strong Bid for Tough Membrane Uses", Chemical Engineering, June 9, pp 19, 1986.

6. Gillot J. and D. Garcera, FILTRA 84 Conf., Paris, Oct. 2-4, 1984.

7. Galaj. S., A. Wicker, J. P. Dumas, J. Gillot and D. Garcera, Le Lait, 64, 129, 1984.

8. Mignonac J. M., D. Poirier, P. Bourdin, M. Bennasar, J. Gillot, D. Garcera and B. Tarodo, FILTRA 84 Conf., Paris, Oct. 2-4, 1984.

9. Poirier D., F. Maris, M. Bennasar, J. Gillot, D. Garcera and B. Tarodo, Ind. Aliment. Agraic., 101, 1, 1984.

10. Guizard C., J. A. Alary, A. Larbot, L. Cot, M. Rumeaau, B. Castelas and J. Gillot, Le Lait, 64, 276, 1984.

11. ALCOA/SCT, technical brochure, "Membralox Ceramic Multichannel Membrane Modules", 1984.

12. Norton Co. technical brochure, "Ceraflo Asymmetric Ceramic Microfilters", 1985.

13. NGK Insulators, technical brochure, "Ceramic Filters", 1987.

14. Anotec Separations Ltd., technical brochure, "Anotec Inorganic Membrane Technology".

15. Bhave, R. R. and H. L. Fleming, AIChE Symp. Ser., 261, 19, 1988.

16. Nakajima, M., N. Jimbo, K. Nishizawa, H. Nabetani, A. Watanabe and S. Nakao paper presented at the Int. Congress Memb. and Memb. Proc., Tokyo, Japan, Jun 8-12, 1987.

17. Kameyama, T., Sep. Sci.. Technol., 14, 953, 1979. 
18. Kameyama, T., M. Dokiya, M. Fujishige, H. Yokokawa and K. Fukuda, Ind. Eng. Chem. Fundam., 20, 97, 1981.

19. Shinji, O., Bull. Chem. Soc., Japan, 55, 2760, 1982.

20. Sun, Y. M. and S. J. Khang, Ind. Eng. Chem. Res., 27, 1136, 1988.

21. Gryaznov, V. M., Dokl. Akad. Nauk, SSSR, 189, 794, 1969.

22. Gyaznov, V. M., Kinet. Katal., 12, 640, 1971.

23. Gyaznov, V. M. et al., U. S. Patent 4,388,479,1983; British Patent 1,342,869,1974; U.S. Patent, 3,849,076, 1974; British Patent 2,056,043A, 1981; British Patent 1,528,710, 1978.

24. Gryaznov, V. M., V. S. Smirnov, L. K. Ivanova and A. P. Michenko, Dokl. Akad., Nauk, SSSR, 190, 144, 1971.

25. Gryaznov, V. M., V. S. Smirnov and M. G. Slinko, Proc. 5th Int. Congr. on Cat., London, $2,1139,1973$.

26. Gryaznov, V. M., V. S. Smirnov and M. G. Slinkn, Proc. 6th Int. Congr. on Cat., London, 2, 894, 1976.

27. Gryaznov, V. M., V. S. Smirnov and M. G. Slinko, Proc. 7th Int. Congr. on Cat., Tokyo, 2, $224,1981$.

28. Nazarkina, E. B. and N. A. Kirichenko, Khim. Teknol. Topl. Masel., 3, 5, 1979.

29. Roshan, N. R., A. P. Miskchenko, V. P. Polyakova, N. I. Parfenova, E. M. Savitsky, E. A. Voitekhova, V. M. Gryaznov and M. G. Sarylova, J. Less Comm. Met., 89, 423, 1983.

30. Gryaznov, V. M., M. M. Ermilova, L. S. Morozova, W. V. Orekhova, V. P. Polyakova, N. R. Roshan, E. M. Savitsky and N. I. Parfenova, J. Less Comm. Met., 89, 529, 1983.

31. Gryaznov, V. M., Platinum Metals Rev., 30, 68, 1986.

32. Gryaznov, V. M., Vestn. Akad. Nauk, SSSR, 3, 21, 1986.

33. Compagnie des Metaux Precieux, French Published Patent Application, 2, 302, 273, France, 1976.

34. Itoh, N., AlChE J., 33(9), 1576, 1987.

35. Hsu, C. and Buxbaum, R. G., Paper presented at the AIChE Annual Meeting in New York, Nov. 1987. 
36. Nagamoto, H. and Inoue, Chem. Eng. Comm., 34, 315, 1985.

37. Di Cosimo, R., J. D. Burrington and R. K. Grasseli, J. Catal., 102, 234, 1986, also U. S. Patent, 4, 571,443, 1986.

38. Michaels, J. N. and C. G. Vayenas, J. Catal., 85, 477, 1984.

39. Nigara, Y. and B. Gales, Bull. Chem. Soc. Japan, 59, 1997, 1986

40. Cales, B. and J. F. Baumard, High Temp.-High Press., 14, 681, 1982.

41. Otsuka, K. and A. Morikawa, Kagaku, Kogaku, 49, 61, 1985.

42. Gryaznov V. H., V. I. Vedernikov and S. G. Gylyanova, Kinet. Katal., 27, 142, 1986.

43. Asadea, M., L. D. Du and M. Ushijima, Proc. 4th Int. Drying Symp., 2, 472, 1984.

44. Asadea, M., and L. D. Du, J. Chem. Eng. Japan, 19, 72, 1986.

45. Asadea, M.. L. D. Du and M. Fuji, J. Chem. Eng. Japan, 19, 84, 1986.

46. Itaya, K., S. Sugawara, K. Arai and Saito, J. Chem. Eng. Japan, 17, 514, 1984.

47. Saito, M., Bull. Chem. Soc. Japan, 55, 2760, 1982.

48. Asaeda, M. et al., U. S. Patent 4692354, 1987; Japanese Patent 192314, 1986.

49. Takamune, N., Japanese Patent 258704, 1987.

50. Abe, F., Japanese Patent, 121616, 1987; Japanese Patent Appl. 301512, 1986; Eur. Patent Appl. 195549.

51. Saito, H. et al., Japanese Patent 274712, 1986.

52. Kimura, H., Japanese Patent 259706, 1986; 254205, 1986; 254204, 1986; 254206, 1986.

53. Oya, H. et al., Japanese Patent 212309, 1986.

54. Kameyama T., K. Fukuda, M. Fujishige, H. Yokokawa and M. Dokiya, Hydrogen Energy Prog., 2, 569, 1981.

55. N. Nourbaksh, I. A. Webster and T. T. Tsotsis, paper presented at the AIChE Annual Meeting, Washington, D. C., Nov. 1988.

56. Abe, F., Eur. Pat. Appl. 228,885, 1987. 
57. Zaspalis V. T., K. Keizer, J. G. Van Ommen, J. R. H. Ross and A. J. Burggraaf, paper 58a, presented at the AIChE National Meeting, Denver, Aug. 1988.

58. Croopnick, G. A. and D. M. Scruggs, U. S. Patent 4,608,319, 1986.

59. Leenaars, A. F. M., K. Keizer and A. J. Burggraaf, J. Mater. Sci., 19, 1977, 1984.

60. Leenaars, A. F. M. and A. J. Burggraaf, J. Membr. Sci, 24, 261, 1985.

61. Leenaars, A. F. M. and A. J. Burggraaf, J. Membr. Sci., 24, 245, 1985.

62. Leenaars, A. F. M. and A. J. Burggraaf, I. Coll. Int. Sci., 105, 27, 1985.

63. Yoldas, B. E., Ceram. Bull., 54, 285, 1975.

64. Visca, M. and E. Matijenic, J. Colloid Interf. Sci., 68, 308, 1979.

65. Itaya, K., S. Sugawara, K. Arai and S. Saito, J. Chem. Eng. Japan, 17, 514, 1984.

66. Mitrovic, M. and L. Knezic, Desalination, 28, 147, 1979.

67. Quinn, J. A., J. L. Anderson, W. S. Ho and W. J. Petzny, Biophys. J., 12, 990, 1972.

68. Riedel, C., and R. Spohr, J. Membr. Sci., 7, 225, 1980.

69. Lee, K. H. and S. J. Khang, Ceram. Eng. Sci. Proc., 8, 85, 1987.

70. Koresh, J. E. and A. Sofer, Separ. Sci. Technol., 18, 273, 1983.

71. Wachtman, J. B. and R. A. Haber, Chem. Eng. Prog., 39, , 1986.

72. Tejin, K. K., Jap. Patent Application 59, 177, 117, 1984. 
VII

$\leadsto$
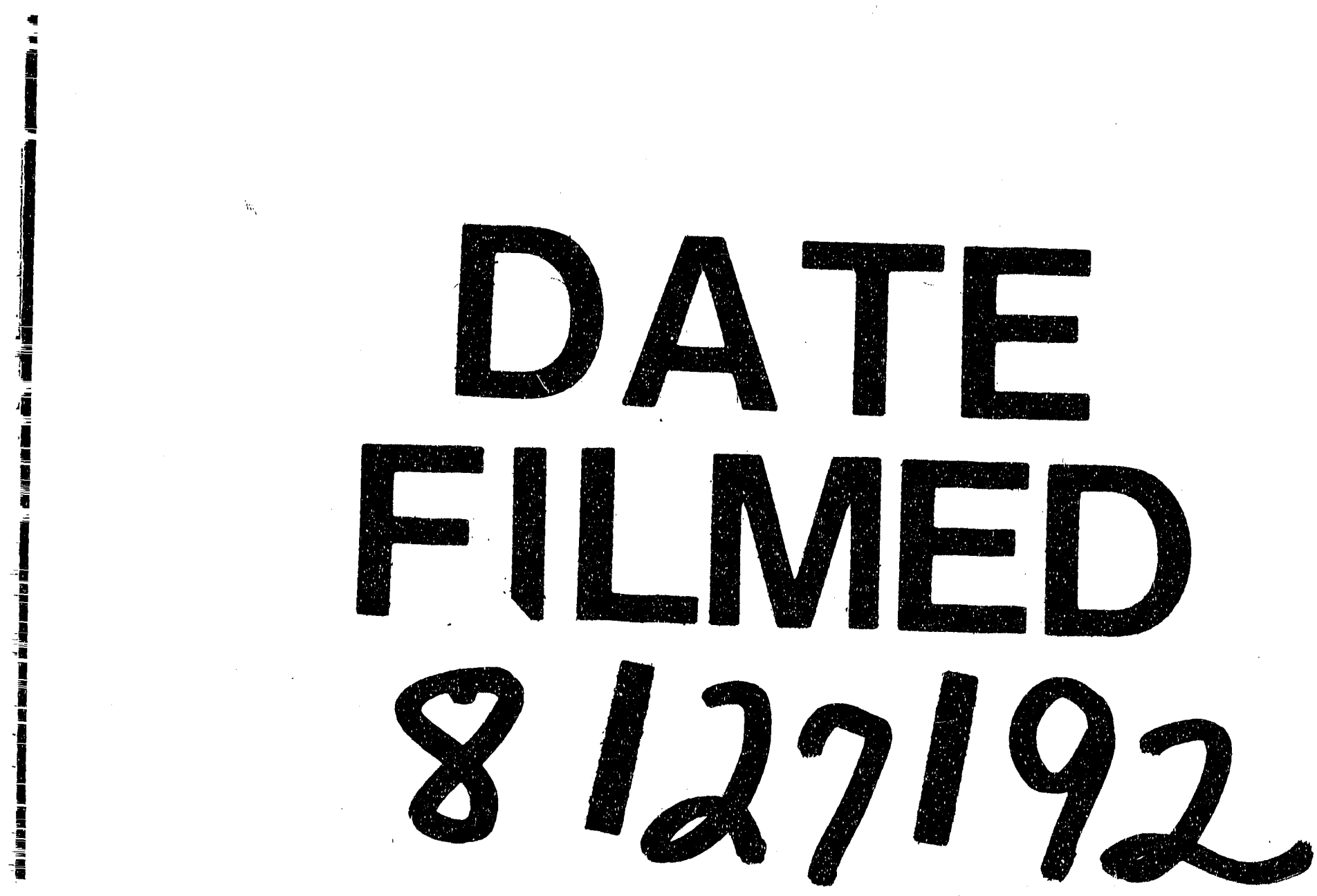


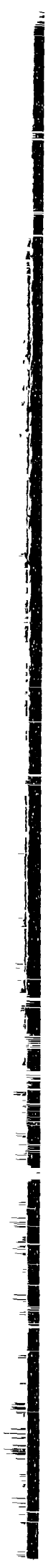

